Delft University of Technology

\title{
A Serious Game for Changing Mindsets About Loans for Home Retrofitting
}

Dikken, Olivier ; Prakash, Kushal ; Roseboom, Bart ; Rubio, Ana ; Østvik, Sander; Bueno , Maijael; Salamon, Nestor Z.; Bidarra, Rafael

DOI

10.1007/978-3-030-63464-3_33

Publication date

2020

Document Version

Final published version

Published in

Games and Learning Alliance

\section{Citation (APA)}

Dikken, O., Prakash, K., Roseboom, B., Rubio, A., Østvik, S., Bueno, M., Salamon, N. Z., \& Bidarra, R. (2020). A Serious Game for Changing Mindsets About Loans for Home Retrofitting. In I. Marfisi-Schottman, F. Bellotti, L. Hamon, \& R. Klemke (Eds.), Games and Learning Alliance : 9th International Conference, GALA 2020, Proceedings (pp. 347-361). (Lecture Notes in Computer Science (including subseries Lecture Notes in Artificial Intelligence and Lecture Notes in Bioinformatics); Vol. 12517 ). Springer

Science+Business Media. https://doi.org/10.1007/978-3-030-63464-3_33

Important note

To cite this publication, please use the final published version (if applicable).

Please check the document version above. 
Green Open Access added to TU Delft Institutional Repository

'You share, we take care!' - Taverne project

https://www.openaccess.nl/en/you-share-we-take-care

Otherwise as indicated in the copyright section: the publisher is the copyright holder of this work and the author uses the Dutch legislation to make this work public. 


\title{
A Serious Game for Changing Mindsets About Loans for Home Retrofitting
}

\author{
Olivier Dikken, Kushal Prakash, Bart Roseboom, Ana Rubio, Sander Østvik, \\ Mijael Bueno, Nestor Z. Salamon, and Rafael Bidarra $\left.{ }^{(}\right)$ \\ Delft University of Technology, Delft, The Netherlands \\ R.Bidarra@tudelft.nl
}

\begin{abstract}
Adding energy-saving products to your house can benefit the economy, the environment and your living comfort. However, these products are very costly, and many people cannot afford them using their own savings. There exist several options for funding these projects, but people do not take advantage of such due to lack of information and the common negative view on using external funding. Psychological objections on taking loans include future time perspective, perception of short time rewards and connotation of loans itself. This paper presents a serious game aimed at changing people's mindset on taking loans to retrofit energy into their homes; Supreme Green Time Machine is a tycoon game in which you can acquire energy-saving products for your home. A main mechanic in the game is the opportunity to take loans to fund the purchase of these upgrades. Combined with other underlying mechanics, such as the time progress and social feedback, the game targets the different psychological objections to long term loans for home retrofitting. From a preliminary evaluation, we conclude that Supreme Green Time Machine effectively succeeds in making players more positive towards using loans to retrofit their homes.
\end{abstract}

Keywords: Serious games $\cdot$ Persuasive games $\cdot$ Home retrofitting • Energy finance $\cdot$ Future time perspective $\cdot$ Sustainability

\section{Introduction}

Due to environmental considerations, there is an increasing pressure to lower our gas emissions and use cleaner energy. Having energy-saving products in a house helps to lower such emissions and brings benefits to the house owner and the people living there. Still, people are hesitant to invest on retrofitting energy to their house due to the high investment cost.

One of the solutions to the high cost of products is for private home owners to take loans to fund their retrofitting project. These loans are often encouraged by the government [10] and have some of the lowest interest rates on the market [14]. However, this is still not a popular solution, as many home owners do not realize the benefits. We approach this problem with the following question: How could 
a game help change people's mindset about using loans to fund energy-saving products for their house?

We target this question by designing and testing a serious game. The game aims at positively changing the player's mindset on taking loans for installing energy-saving products at home. Using games for educative and persuasive purposes has grown in popularity the last years, including environmental awareness $[1,3,13,16]$. The financial aspect makes the retrofitting a complex problem, and there are several underlying psychological factors that need to be tackled together in order to change someone's mindset. Nonetheless, people's generally negative connotation to loans, the general focus on short term rewards - and the unavailability of future time perspective (FTP) visualizations, weight heavily on how home owners feel about taking loans for investments such as retrofitting.

We present Supreme Green Time Machine, a serious game to change this mindset and create a positive view on the long-term benefits of loans applied to retrofitting. The FTP problem is tackled by speeding up time to quickly show the player the long term rewards. The game provides a simplified loan system that allows the player to pay back their loans using their savings - providing a more positive connotation towards repaying loans. As for the problem of people's unawareness of the short term benefits of energy-saving products, we use a feedback system providing both visual and statistical instructional information, which emphasises the immediate impact of their actions.

Supreme Green Time Machine was evaluated through surveys, answered during playtest-sessions, with people in the target audience of private home owners.

\section{Related Work}

Serious games, when integrated into real life, have previously been shown to have positive impact on the attitude and behaviour of household owners when it comes to energy conservation [7]. Quite a few games have been made within the energy domain, including: The Power House [2], Energy Chickens [13], EcoIsland [11] and Powersaver Game [8]. The latter study contains a comparison of previous energy games and points out some shortcomings when it comes to the implementation of gamification and the lack of pre- and post-measurements.

Previous research $[9,12]$ point out that the lack of information about the different aspects of house retrofitting is an important factor as to why there have been so few home retrofits. In a research done on energy labels for dwellings [5], they conclude that the use of energy efficiency labels on homes can help with stimulating people to get a retrofit for their home. This shows that using visual feedback can give people a more positive mindset towards retrofitting their house. Nonetheless, the main reason people have interest in installing insulation is to improve comfort, while the main driver behind the interest in installing solar panels is the perceived cost reductions [4].

Furthermore, people discount the utility of future rewards depending on their future time perspective - the concept on how people perceive results that are happening in the distant future. Most of the people do not appreciate rewards 
that will happen in more than fifteen to twenty years into the future [15]. This raises a challenge in our domain, as it usually takes several years before home owners reap the rewards from retrofitting their houses. Research suggests that rewards at a time beyond a player's "future window" have no value at all to the player [6]. This is mainly due to lack of interest and not because impulsive instant-reward decisions get priority. Interestingly, different players have different future time perspectives: a player with a deep/long FTP sees their current actions as more valuable because they lead to future goals that are more strongly valued [15]. These findings can be useful to interpret why a player does not partake in a project with guaranteed long term profits. These are mindsets that we try to overcome in the design and evaluation of our game.

Finally, different incentives have different effects on the present performance of an individual. Generally stating that an activity serves the participant's future does not yield positive effects, as it does not allow the participant to fully grasp the specific meaning and importance of the activity [15]. Furthermore, pointing out the future importance of one's present behaviour might only result in beneficial effects if people have an optimistic outlook toward their future. This shows the importance of not only stating long term gains to the player, but also make them aware of the short term benefits. These aspects are targeted within our game and described in the following.

\section{Game Design}

Supreme Green Time Machine aims at changing the player's mindset on taking a loan to fund the retrofitting of their house. To achieve this, we address psychological aspects such as future time perspective (FTP), perception of short term rewards and the negative connotation of loans.

The game is a tycoon-type game aimed at private home owners. The essence of the game is to upgrade your house with energy-saving products to benefit from living comfort and environmental improvements. It encourages players to consider taking loans to help paying for these upgrades. The game also combines a time speed-up mechanism and a reinforced feedback system, which increases the impact of the simulation by highlighting the positive outcome of investing, through loans, on energy retrofitting. An interactive play-through lasts about ten minutes, running an experience of fifteen years of in-game time. This strongly helps realizing the long term rewards, as well as the short term personal, environmental and social benefits.

\subsection{Gameplay}

The gameplay revolves around the player's house in a virtual neighborhood. The player will be interacting with and observing the simulation to monitor how their upgrade-choices and outside events play out. During this time, the player will also be buying energy-saving products to improve their home, while facing seasonal challenges (e.g., weather, power failures, etc.) and receiving occasional 
feedback (e.g., the neighbors' competition for greener and more efficient homes). The player has to balance the environmental and living comfort scores of the house along with their finances.

To help the player on the financial side, the option of taking a loan is available to fully or partially pay for buying a product. An upgrade menu shows players the products they can install into the house along with the funding alternative. Through a clear information overview, the player can keep track of the progression of his/her house, as well as compare the different strategies used by the neighbors - from which useful insights can be drawn. The game mechanic is balanced to help the player get the best of the possible loans: if desired, a joker can be used once to go back in time two years and try applying a different strategy. At the end of the game, players get to see how well they fared against the neighbors, and who managed to achieve the best environmental impact, living comfort and financial outcome. An overview of the gameplay is illustrated in Fig. 1.

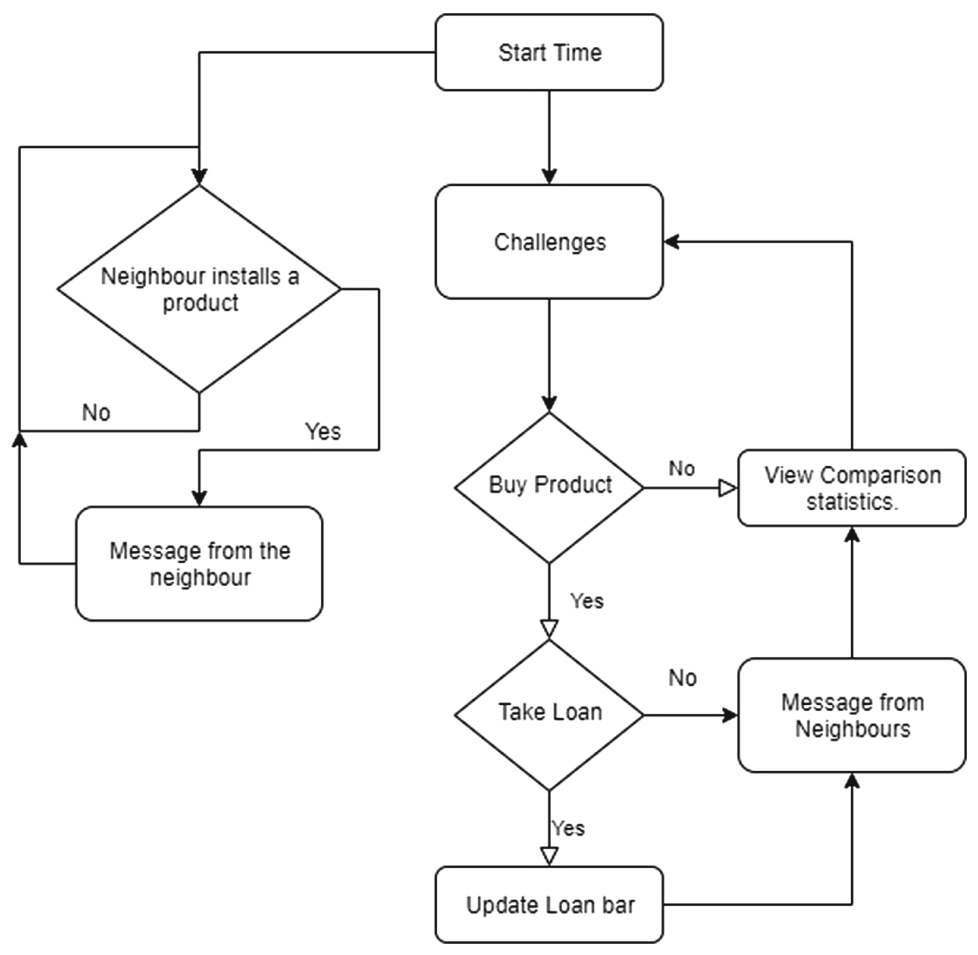

Fig. 1. Supreme Green Time Machine game flow. Players take care of their home by buying and installing energy-saving products, while, in parallel, the neighborhood runs similar retrofitting actions. At the end of a fast-forward simulation, players are presented with the benefits of taking a loan to upgrade their houses. 


\subsection{Persuasion Mechanisms}

The mechanisms included in the game design of Supreme Green Time Machine to facilitate a gentle change in the players' mindset include: (i) providing a future time perspective (FTP) through an accelerated simulation, (ii) a visual feedback system that shows the benefits of greener retrofitting solutions for the house and neighborhood, (iii) a social feedback loop based on common neighborhood emotions, and (iv) a simplified financial model that encourages the players to confidently take a loan with long term returns. In the following, we describe the design and mechanics details.

Accelerated Time Simulation. While home owners could read about the benefits of house retrofitting in, say, a brochure or website, the non-personal character of these texts does not provide a direct FTP, nor the appeal to research how that would apply on their own house and neighborhood. Instead, through actively visualizing and experiencing their options in the game, the long term effects of the players' choices are brought directly to their attention, elucidating what otherwise would just seem abstract to them. This simulation allows players to "quickly" experience events that would spread over fifteen years, and draw practical conclusions of their consequences.

Visual Feedback System. The visual feedback system notifies players of the effects of their different actions. Instead of plainly telling the player 'what causes what', we chose to discretely raise awareness of the short term benefits that come with installing energy-saving products to their homes. After deploying a product, the player scores on financial, environmental and living comfort are updated and visualized in the environment. Seeing these direct benefits of each product, players get encouraged to consider buying specific products that further increase scores on the long term. Moreover, these notifications help conveying the impact on the environment around the player's house. For example, if environmental
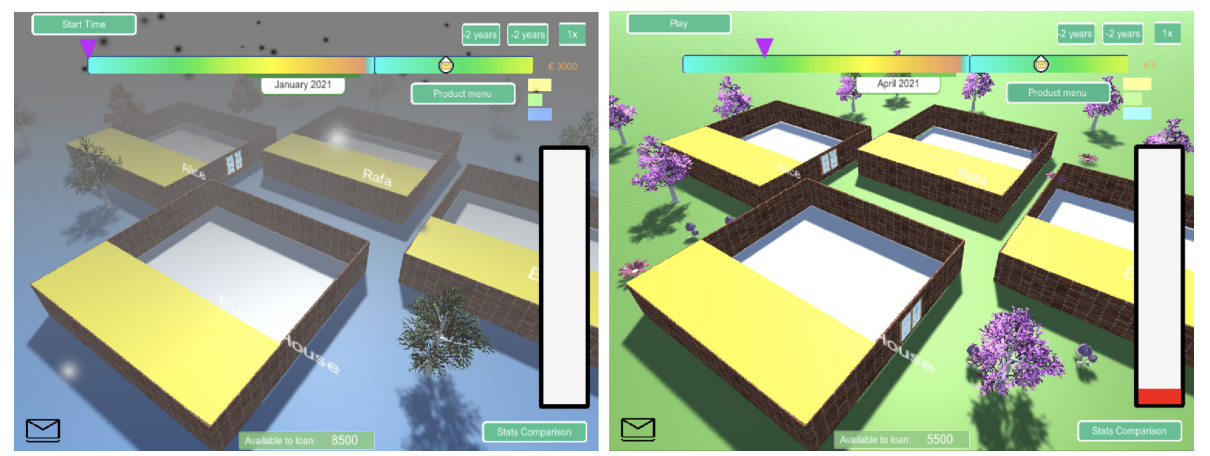

Fig. 2. Fog is present while the environmental score is low (left), and will disappear as the player install greener products and influences the neighbors to take similar actions (right). 
scores get low, pollution clouds represented by fog start forming, in analogy to the bad air quality in the real world. Implicitly, players are stimulated to take action, installing greener products (see Fig. 2).

Social Feedback Loop. In addition to the visual feedback above, players can also be socially challenged to improve the overall neighborhood environmental conditions, by being confronted with their neighborhood score. Living in the same area, and often with similar financial and social status, neighbors tend to do status comparisons in real life. This recognizable behavior is mimicked in the game, further increasing the player's immersion and influencing their choices.

Receiving feedback from your neighbors - who know what you have installed - is another effective form of short term reward. This is achieved in the game through short messages from the neighbors, which target player's emotions, namely satisfaction and jealousy. At times, a neighbor will compliment after the player installed a product that improves the whole environment. This might induce a positive, satisfactory emotion, creating positive feelings as instantaneous rewards. Conversely, some neighbors might be a step ahead within the game, exhibiting better scores due to a smarter strategy; in that case, they will unmistakably make the player aware of this through appropriate messages. These might induce some jealousy, but hopefully also inspire to reflect and learn, as well as strive for competition.

Financial Model. Supreme Green Time Machine is supported by a simplified financial model to enable taking loans and purchasing energy-saving products. The player starts with a base capital that can be used to buy products. In addition, the player receives a yearly amount representing the household income. Depending on the price of the product of your choice, it can be either integrally paid with saved money or partially financed by taking a loan. Loan amounts are limited each year, and the total needs to be taken into consideration when choosing a purchasing strategy.

Each product in the game will "give back" a certain amount of money every year, i.e. the value of its energy savings. Each year after the product is installed, its savings will be subtracted from the loan that was used for that product; when this loan gets to zero, that amount will go directly into the capital of the player. The incoming capital is also affected by simulation challenges the player is faced with, such as a variety of Winter and Summer events. In case the household is not prepared for such seasonal events, a certain amount is deduced; otherwise, the household withstands it, indicating a well planned investment. With such events and a measurable return on investment, the financial model allows players to quantify the extent to which the the invested capital is returned, as well as to get a clear insight into the timeline of that process. A complete overview of the financial model used is presented in Fig. 3. 


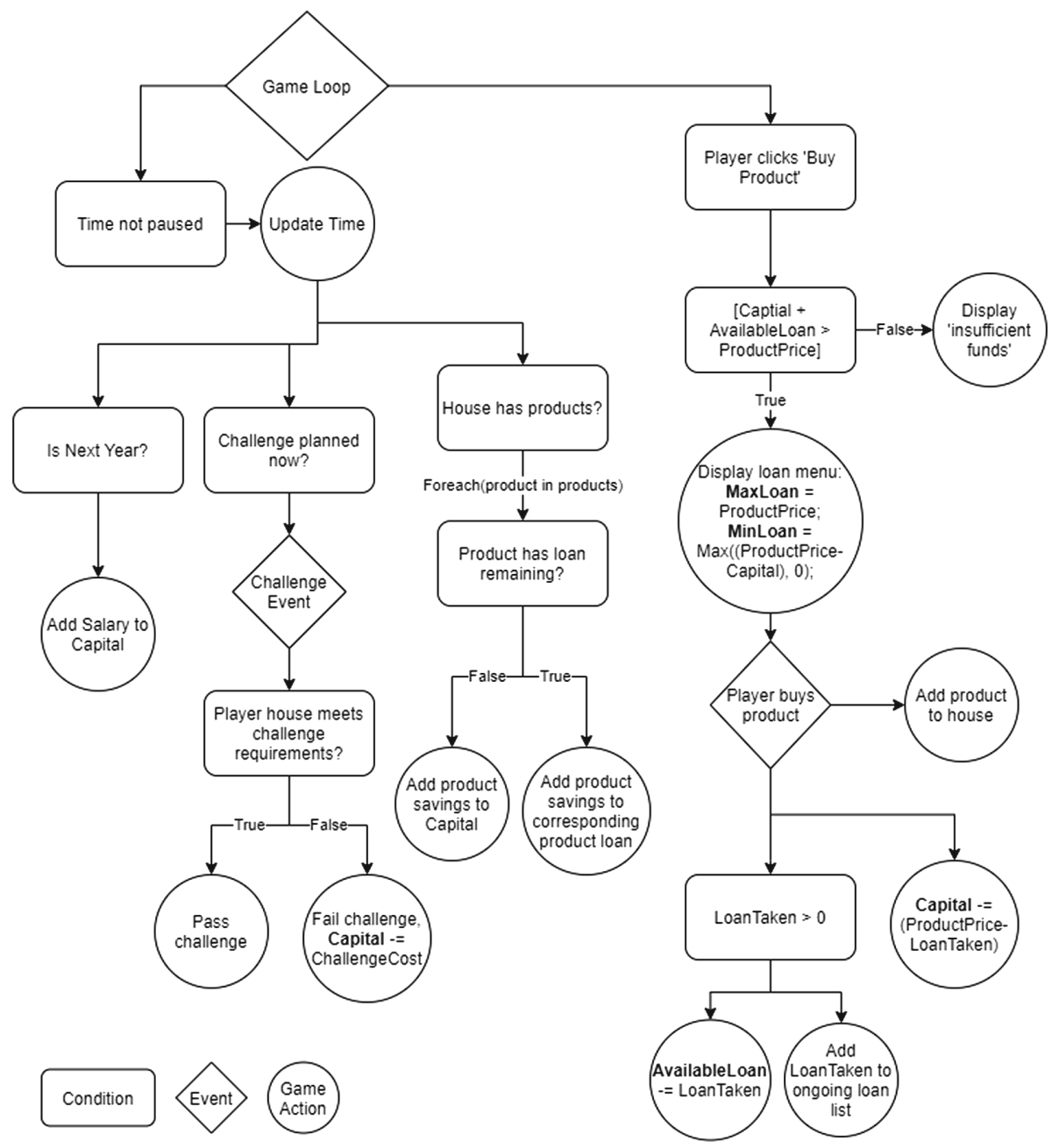

Fig. 3. Complete diagram of the financial model, including loans, seasonal events, annual salary and return on investment.

\section{Evaluation}

Supreme Green Time Machine's potential on changing people's mindset was validated through a user study based on the following hypothesis: A game can be significantly more effective than a plain informative text in positively changing the mindset of a house owner, regarding taking loans to retrofit their house. Assessing this hypothesis allows us to validate if the game adds any value to the solutions already in use to inform people about retrofitting and loans. We evaluated whether the game positively informs players on this matter by conducting multiple playtesting sessions with pre- and post-game questionnaires. 
The playtesting sessions had a total of 51 participants, all within our target group: private home owners. The participants were presented with an informative text, which consisted of information on energy-saving products, their price and their impact. The text also stressed the importance and advantages of having more house owners retrofit their homes. Additional information on how to use loans to fund these products was also provided. The reason for an informative text as part of the (pre-)evaluation is to comply with our hypothesis, and also minimize potential bias of uninformed home owners: participants knowing little or nothing about energy-saving products might have answered that the game heavily improved their mindset as a substantial volume of novel information was presented.

Next, the participants were given the pre-game survey. In this survey, we asked about their mindset towards energy-saving products, using loans to fund them as well as some general questions on their current living situation. The questionnaire is available on Appendix A. After the first survey was conducted, the participants played the game for one session (ten minutes). Finally, they were requested to answer the follow up survey, evaluating their new mindset on the previously questioned aspects (see Appendix B). Evaluated answers were collected as a 7 point Likert-scale.

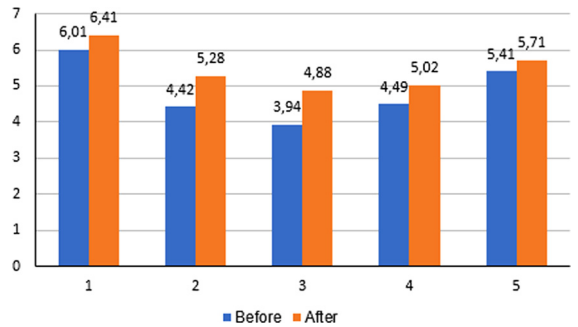

Fig. 4. Outcome of both surveys before and after the game. Questions are presented in Appendices A and B. (Color figure online)

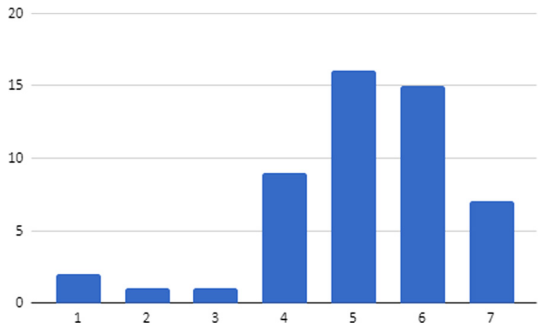

Fig. 5. Distribution of participants' answers to question $\mathrm{B} \# 8$, on the perceived degree of extra information provided by the game.

Figure 4 shows the survey results for the Likert answers. Blue and the orange bars show the average score given by the participants for the question in the preand post-game surveys, respectively. The average score is higher for all of the questions in the survey after the game. The first two questions (Appendix A \#7 and \#8 (pre), Appendix B \#2 and \#3 (post)) consist of choices regarding six different products. In order to generate the score per participant, we averaged the scores per product given by the participant. In the third bar (questions \#9 and \#4, pre- and post), we asked how likely the participant was to use loans to fund the installation of an energy-saving product and observed an increase of almost 
one point. The participants went from averaging at almost 4 (neutral) to just roughly 5 (somewhat likely) after playing the game. Overall, the questionnaires show that the game did change the participants attitude towards being more likely to acquire energy-saving products and use loans to fund them.

The participants were also asked to which degree they felt that the game provided them with new information. Figure 5 shows that a majority of the participants felt that the game gave them extra information, averaging a score of 5.14 ( 1 equals "no new information" and 7 "a lot of new information"). With regards to our hypothesis, we can affirm that the game does add value to existing solutions, and manages to improve the mindset of the people playing it in a positive way with regards to using loans to retrofit their houses.

\section{Conclusion}

Despite all its advantages, retrofitting a house with energy-saving products still struggles with a number of financial, social and psychological objections, including: a lack of future time perspective, deficient perception on short term benefits, and a general negative connotation of taking loans.

We investigated how a game could help change people's mindset on taking loans to fund such projects. For this research, we designed Supreme Green Time Machine, a novel tycoon-type game aimed at private home owners. The game design features a careful combination of persuasion mechanisms, providing future time perspective through accelerated simulation, instant visual feedback, a powerful social feedback loop, and an effective financial model.

Our prototype game evaluation has shown that people previously hesitant did adopt a more positive attitude towards taking loans for greener energy after playing the game. We can therefore conclude that Supreme Green Time Machine positively helps change people's mindset about taking loans to fund their home retrofitting projects.

Acknowledgments. The authors thank Gerard van Smeden and De Energiebespaarders for their help and expertise during the development and evaluation of the game.

\section{A Survey after text}

Thank you for participating in this survey! You have read an informative text about energy savings. We would now like to know about some of your views on this topic and your thoughts on installing energy saving products to your home. 
${ }^{*}$ Required

1. Please enter your name (This will only be used to link your two surveys together) *

\section{What is your age? *}

Mark only one oval.
Under 20
$20-29$
$30-39$
$40-49$
$50-59$
$60-69$
$70-79$
$80+$

3. In what type of home do you live in? * Mark only one oval.
Apartment

\section{Cornerhouse}
Detached house
Duplex
Row house
Other

4. For how many years have you been living in your current house? * Mark only one oval.

Less than 1 year

1 - 2 years

2 - 3 years

3 - 5 years

$5-7$ years

7 - 10 years

$10+$ years 
5. Do you have any of the following energy saving products in/on your house already? * Tick all that apply.

$\square$ Solar Panels
$\square$ Floor insulation
$\square$ Roof insulation
$\square$ Wall insulation
$\square$ Window insulation
$\square$ Electric heating pump
$\square$ None of the above

6. If you have one of the above mentioned energy saving products, did you use a loan to fund the installation of that product? *

Mark only one oval.
Yes, for all of them
Yes, for some of them
No
I did not install them

7. If these products were free, how likely would you be to install them? * Mark only one oval per row.

Very
Solar Panels
Floor insulation
Roof insulation
Wall insulation
Window
insulation
Electric heating
pump

8. With their normal cost, how likely are you to install any of the energy saving products? * Mark only one oval per row.

Very
Solar Panels
Floor insulation
Roof insulation
Wall insulation
Window
insulation
Electric heating
pump


9. How likely are you to use a loan to fund the installation of a energy saving product? * Mark only one oval.

very unlikely

Survey after text

10. How important are the following factors to you when it comes to the reason for installing energy saving products to your home? *

Mark only one oval per row.

\section{Not important Neutral Important}

Good for the environment
Increased living comfort
Saving money

11. How likely are you to further explore your options when it comes to getting loans and/or subsidies for installing energy saving products? *

Mark only one oval.

very unlikely $\square$

12. You have read the example of the solar panels paying down their own price in 10 years. How does this fact impact your decision on acquiring energy saving products? *

Mark only one oval.

Very negatively

\section{B Survey after game}

Thank you for participating in this survey! You have played our game about retrofitting your house with energy saving products. We would now, again, like to know about some of your views on this topic and your thoughts on installing energy saving products to your home. 


\section{Please enter your name (This will only be used to link your two surveys together) *}

2. If these products were free, how likely would you be to install them? * Mark only one oval per row.

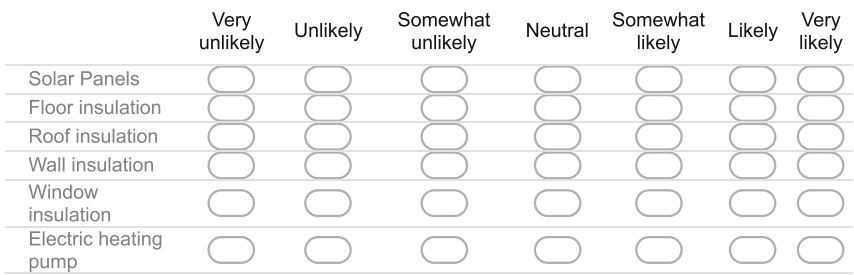

3. With their normal cost, how likely are you to install any of the energy saving products? * Mark only one oval per row.

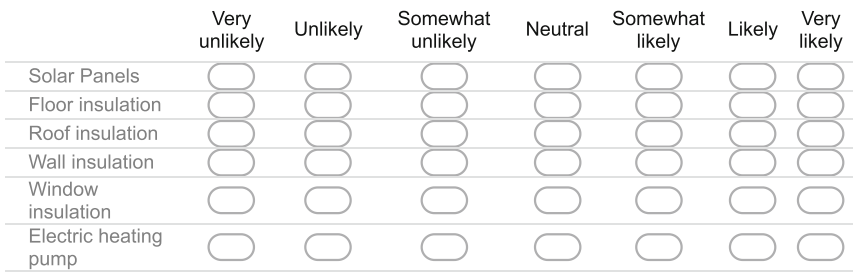

4. How likely are you to use a loan to fund the installation of a energy saving product? * Mark only one oval.

$\begin{array}{llllllll}1 & 2 & 3 & 4 & 5 & 6 & 7 \\ \text { very unlikely } \square & \square & \square & \end{array}$

5. How important are the following factors to you when it comes to the reason for installing energy saving products to your home? *

Mark only one oval per row.

Not important Neutral Important

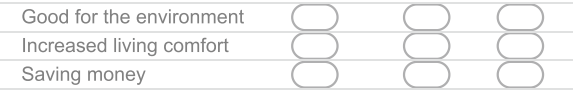



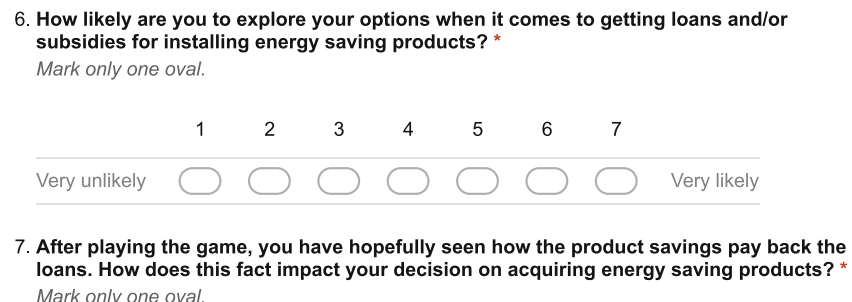
Mark only one oval.

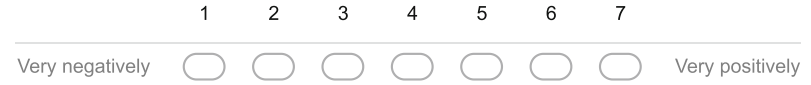

8. To what degree do you feel that the game gives you extra information beyond the text you read earlier? *

Mark only one oval.

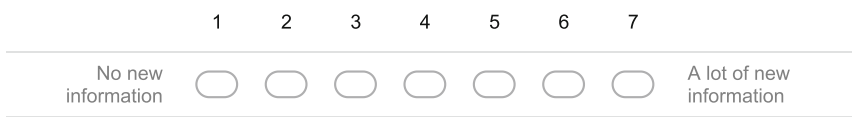

\section{References}

1. Appel, Y., et al.: A serious game to inform young citizens on canal water maintenance. In: Liapis, A., Yannakakis, G.N., Gentile, M., Ninaus, M. (eds.) GALA 2019. LNCS, vol. 11899, pp. 394-403. Springer, Cham (2019). https://doi.org/10. 1007/978-3-030-34350-7_38

2. Bang, M., Torstensson, C., Katzeff, C.: The powerhhouse: a persuasive computer game designed to raise awareness of domestic energy consumption. In: IJsselsteijn, W.A., de Kort, Y.A.W., Midden, C., Eggen, B., van den Hoven, E. (eds.) PERSUASIVE 2006. LNCS, vol. 3962, pp. 123-132. Springer, Heidelberg (2006). https:// doi.org/10.1007/11755494_18

3. Mac an Bhaird, L., et al.: Learning geothermal energy basics with the serious game hotpipe. In: Liapis, A., Yannakakis, G.N., Gentile, M., Ninaus, M. (eds.) GALA 2019. LNCS, vol. 11899, pp. 312-321. Springer, Cham (2019). https://doi.org/10. 1007/978-3-030-34350-7_30

4. Collins, M., Curtis, J.A.: Identification of the information gap in residential energy efficiency: how information asymmetry can be mitigated to induce energy efficiency renovations. Technical report, The Economic and Social Research Institute (ESRI), Dublin (2017)

5. Comerford, D.A., Lange, I., Moro, M.: Proof of concept that requiring energy labels for dwellings can induce retrofitting. Energy Econo. 69, 204-212 (2018)

6. Fellows, L.K., Farah, M.J.: Dissociable elements of human foresight: a role for the ventromedial frontal lobes in framing the future, but not in discounting future rewards. Neuropsychologia 43(8), 1214-1221 (2005)

7. Fijnheer, J.D., van Oostendorp, H.: Steps to design a household energy game. In: de De Gloria, A., Veltkamp, R. (eds.) GALA 2015. LNCS, vol. 9599, pp. 12-22. Springer, Cham (2016). https://doi.org/10.1007/978-3-319-40216-1_2

8. Fijnheer, J.D., van Oostendorp, H., Veltkamp, R.: Household energy conservation intervention: a game versus dashboard comparison. Int. J. Serious Games 6(3), $23-26$ (2019) 
9. Hrovatin, N., Zorić, J.: Determinants of energy-efficient home retrofits in slovenia: the role of information sources. Energy and Buildings 180, 42-50 (2018)

10. Kerr, N., Winskel, M.: Private Household Investment in Home Energy RetrofitReviewing the Evidence and Designing Effective Public Policy. ClimateXChange, Edinburgh (2018)

11. Kimura, H., Nakajima, T.: Designing persuasive applications to motivate sustainable behavior in collectivist cultures. PsychNology J. 9, 7-28 (2011)

12. Li, I., Magner, P., Sanders, C.: Increasing homeowner demand for energy efficiency retrofits: recommendations for the north carolina building performance association. Master's thesis, Nicholas School of the Environment, Duke University, North Carolina, USA (2017)

13. Orland, B., Ram, N., Lang, D., Houser, K., Kling, N., Coccia, M.: Saving energy in an office environment: a serious game intervention. Energy and Buildings 74, $43-52(2014)$

14. Schleich, J., Faure, C., Meissner, T.: Adoption of retrofit measures among homeowners in eu countries: The effects of access to capital and debt aversion. Technical report, Working Paper Sustainability and Innovation (2019)

15. Simons, J., Vansteenkiste, M., Lens, W., Lacante, M.: Placing motivation and future time perspective theory in a temporal perspective. Educ. Psychol. Rev. 16(2), 121-139 (2004). https://doi.org/10.1023/B:EDPR.0000026609.94841.2f

16. Yiannakoulias, N., Gordon, J.N., Darlington, J.C.: The decision game: a serious game approach to understanding environmental risk management decisions. J. Risk Res. 23(1), 81-94 (2020) 